\title{
Exploration and Analysis of Strain Softening Phenomena of L6 Steel
}

\author{
Sanket Inamdar ${ }^{*}$, Manoj Ukhande ${ }^{2}$, Prashant Date ${ }^{3}$, Shyam Takale ${ }^{2}$, RKP Singh ${ }^{1}$ \\ ${ }^{1}$ Kalyani Centre for Technology \& Innovation, Bharat Forge Ltd. -411036, India. \\ ${ }^{2}$ R\&D CDFD Engineering, Bharat Forge Ltd. -411036, India. \\ ${ }^{3}$ Indian Institute of Technology Powai, Mumbai -400076 India. \\ * Corresponding author. Tel.: 02067271993; email: Sanket.inamdar@bharatforge.com \\ Manuscript submitted April 10, 2017; accepted August 8, 2017. \\ doi: 10.17706/ijmse.2017.5.3.116-122
}

\begin{abstract}
It is a necessity of modern forging industries to explore new materials for hot forging dies, which gives better quality of forging with extended fatigue life and less economic aspects. L6 Steel is one of the material for modern metal forming industries, which mollifies all the benchmarks and requirements. PreMature fatigue failure of forging dies is always an unpredictable and economical damage for any metal forming industry. L6 Steel is a high strength material to avoid die cracking during complex phenomenon of hot forming process. L6 steel, which when subjected to load, will get softened and this is strain softening. In this paper, numerous experiments have been carried on L6 steel material to evaluate cyclic Stress - strain behavior of this material. This research leads us to evaluate and explain phenomenon regarding strain softening and its behavior during low cycle fatigue test. Low cycle fatigue test is carried out on MTS fatigue test machine at fully reverse loading condition $\mathrm{R}=-1$. Also strain softening effect on forging metal forming process is explained in detail. The failed samples during low cycle fatigue test further investigated metallurgically on scanning electron microscopy. Material micro mechanisms further investigated by EBSD technique. Finally the study concludes that, strain softening phenomenon plays a vital role in the fatigue failure of metal forming dies.
\end{abstract}

Keywords: Strain softening, L6 steel, cyclic stress-strain behavior, micro mechanisms.

\section{Introduction}

Forging is a metal forming process used to manufacture critical geometry components which are difficult to manufacture by other modes of production. Metal Forming, it is a process that has been constantly revolutionizing and evolving since the concept of fire. In today's era, the markets of automotive, aerospace, defense and industrial products are controlled by the countries which are producing the accurate metal parts using most cost efficient process control [1]. As long as there is no material stronger cheaper, and abundant then metallic material, the world will forever revolve around those, who can control and form it the best. Even though forging is not a new science. It has been constantly getting evolved with the help of super computers and finite element modeling. Recently it has become more popular and inexpensive way of crafting net shaped and near to net shaped metal products with less design time and cost. As technology is progressing, the spectrum of physical size of product being generated is becoming larger with smaller tolerances. In that forging is standing well ahead of all.

Wear of forging dies is a predominant issue and that is uncontrollable. Another unwanted phenomenon is 
fatigue failure and plastic deformations, occurring frequently in hot forging process. Prediction of die failure due to plastic deformation will be an enormous step for the forging industry[2].

\section{Experimentation}

\subsection{Pre-Processing on Material}

The die material selected for present investigations is L6 steel. Cylindrical shaped samples were used for performing thermal fatigue experiments. Sample preparation involved following stages;

1) Heat treatment of raw material (annealed) with different austenizing temperatures.

2) Machining to dimension as per ASTM E606, with surface roughness of 0.3 to 0.5 Ra.

3) Nitriding using ammonia gas nitriding to obtain desired case depth

As shown in Figure 1; Heat treatment was carried out using two different austenizing temperatures followed by triple tempering to obtain final hardness values of $42 \mathrm{HRc}$; Later these samples were machined to finished dimension as mention above and subject to surface nitriding treatment using ammonia gas nitriding technique.

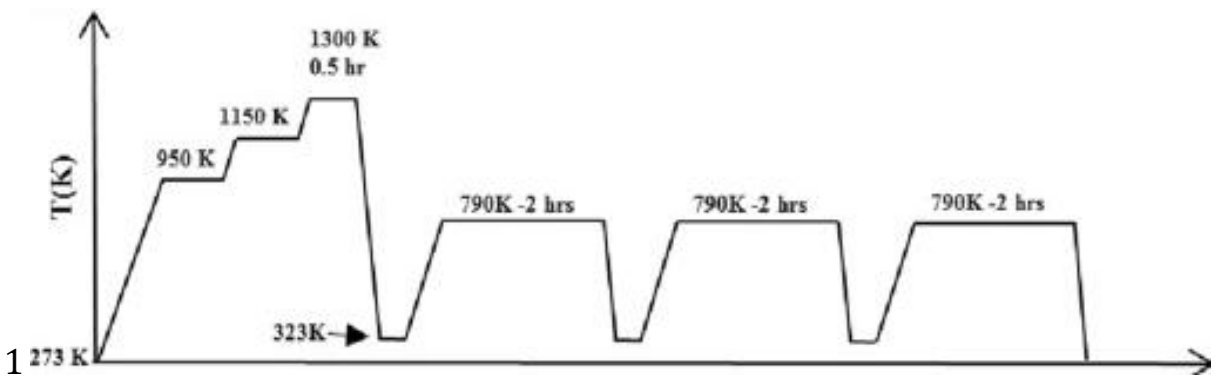

Fig. 1. Heat Treatments and triple tempering for $42 \mathrm{HRc}$.

\subsection{The governing equations used for heating and cooling are as below}

1) Heat transfer equation [2]

$\nabla(-\mathrm{k} \nabla \mathrm{T})=\mathrm{Q}-(\rho \mathrm{Cpu} . \nabla \mathrm{T})$

Where, $\mathrm{k}$ - Thermal Conductivity,

Q - Heat source,

$\rho$ - Density,

$\mathrm{C}_{\mathrm{p}}$ - Specific heat capacity at constant pressure \&

$\mathrm{T}$ - Temperature

2) Induction heating with high frequency [2]

$\mathrm{Qv}=\sqrt{3} \mathrm{~V} I \cos \varnothing$

Where, $Q_{v}$ - Power per unit volume of heat source,

$$
\begin{aligned}
& \text { V - Voltage, } \\
& \text { I - Current, } \\
& \varphi \text { - Power factor, }
\end{aligned}
$$

3) Incompressible Navier-Stokes equation

$\rho \mathrm{l}(\mathrm{u} . \nabla) \mathrm{u}=\nabla[-\mathrm{pI}+\eta(\nabla \mathrm{u}+(\nabla \mathrm{u}) \mathrm{T})]+\mathrm{F}$

Where, $\rho_{1}$ - Density of fluid,

$\eta$ - Dynamic viscosity,

$\mathrm{u}$ - Velocity in $\mathrm{x}$-direction

4) Solid mechanics 
This module was only used for coupling the temperature parameters with the coefficient of thermal expansion of the material which is,

$\alpha=4.02 \mathrm{E}-8 * \mathrm{~T}$

Where, $\mathrm{T}$ - Temperature $(\mathrm{K})$

$\alpha$ - Coefficient of thermal expansion ( $\mathrm{m} / \mathrm{m} \mathrm{K}$ )

\subsection{Boundary Conditions}

1) Heating [3]

$\mathrm{I}=220 \mathrm{~A}$ for $(0+\mathrm{it})<\mathrm{t}<(5+\mathrm{it})$ where, $\mathrm{t}=$ Time

$\mathrm{V}=320 \mathrm{~V}$ for $0<\mathrm{t}<5 \mathrm{t}=0-4200$ seconds

$\varphi=85-90 \% \mathrm{i}=0: 1: 300$

$\mathrm{f}=12 \mathrm{kHz}$ where, $\mathrm{f}=$ Frequency

\subsection{Low Cycle Fatigue Test on MTS}

Low cycle fatigue testing is carried out in Kalyani Centre for Technology and Innovation, to generate strain life curves for L6 Steel Material at various conditions. These conditions are as follows.

1) Plain sample without any surface treatment at room temperature $\left(23^{\circ} \mathrm{C}\right)$

2) Plain sample without any surface treatment at elevated temperature $\left(350^{\circ} \mathrm{C}\right)$

3) Nitrided sample at room temperature $\left(23^{\circ} \mathrm{C}\right)$

4) Nitrided sample at elevated temperature $(350 \mathrm{C})$

Elevated temperature is taken $350{ }^{\circ} \mathrm{C}$ as this temperature is measured immediately after forging of a component. Nitriding parameters are same as of sample S2C1. Parameters specified for tests are as follows.

Table 1. Parameters for Low Cycle Fatigue Test

\begin{tabular}{|c|c|c|c|}
\hline Sr. No & Parameter & Room Temperature & Elevated Temperature \\
\hline 1 & Frequency & $3 \mathrm{~Hz}$ & $3 \mathrm{~Hz}$ \\
\hline 2 & No. of cycles & 20000 & 20000 \\
\hline 3 & Strain & $0.001-0.1$ & $0.001-0.1$ \\
\hline
\end{tabular}

The specimen, which is used for this test is dumbbell shaped threaded sample, as shown in Fig. 2.

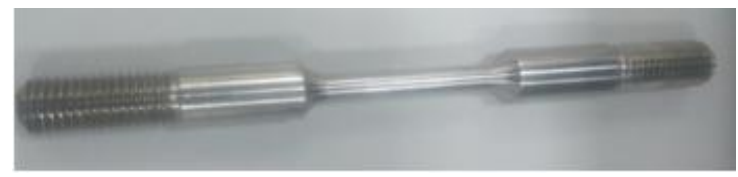

Fig. 2. Specimen for low cycle fatigue test.

This specimen is loaded on MTS machine and strain value is provided to software of this machine. With extensometer attached to gauge length of the sample we can control and measure strain in specimen. If sample completes 20000 axial cycles then sample is removed and next sample is mounted on machine with increase in strain rate. Loaded sample on machine is shown in Fig.3 and failed samples are in Fig 4

\section{Results and Discussion}

\subsection{Tensile Test results and Analysis}

Tensile test has been carried out to find out material properties and also to analyze deformation of the 
material. Following Fig. 3 shows stress strain curve for die steel material. By this curve we can say that yield point of this material is $1050 \mathrm{MPa}$ and UTS is around $1250 \mathrm{MPa}$. This curve helps to differentiate between plastic phase and elastic phase.
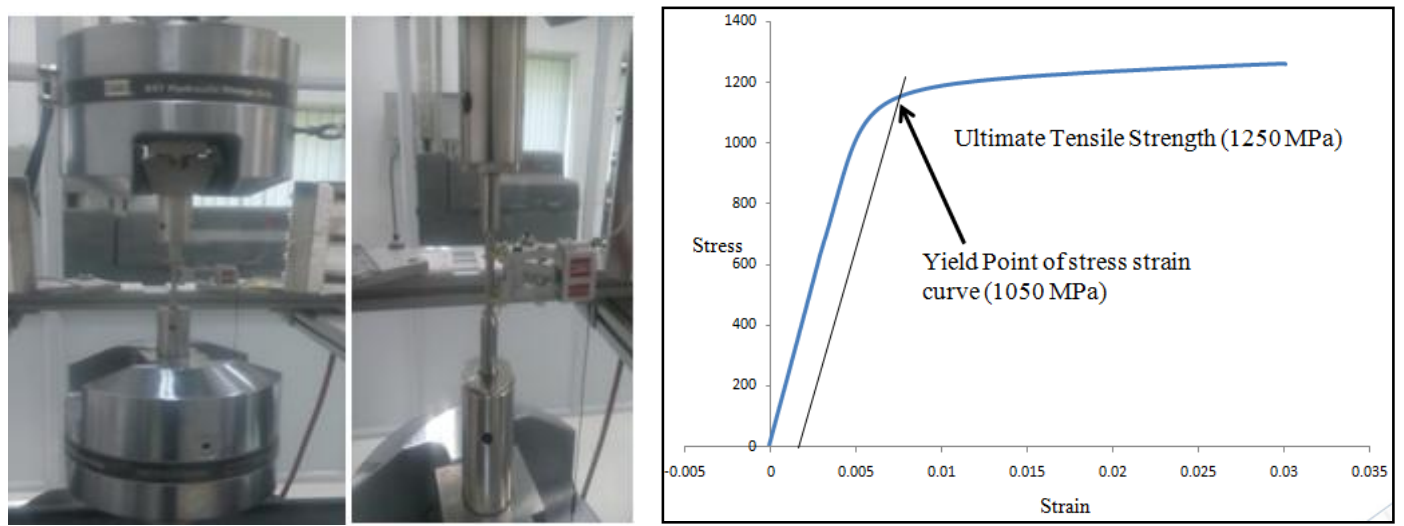

Fig. 3. Specimen for tensile test mounted on MTS. Stress-strain curve for die steel material.

From stress-strain curve it is concluded that, if stresses in die are above yield point (1050 MPa), plastic deformation is prone to happen in die. So maintaining die stresses below $1050 \mathrm{MPa}$ leads to only elastic deformation of the die. This elastic deformation cannot be controlled as this is prone to happen in the die. Limiting this die deflection to a certain limit is also important. Maximum deflection of the die in above case is $0.89 \mathrm{~mm}$, maximum strain in die is 0.007 and maximum stresses are around $1145 \mathrm{MPa}$. Stresses up to yield point i.e. $1050 \mathrm{MPa}$ is consider as elastic stresses so equivalent strain to $1050 \mathrm{MPa}$ is 0.005 . Considering these values are limiting values for elastic deformation. And above that can be considered as plastic deformation.

\subsection{Cyclic Testing Results and Analysis}

To analyze actual deformation in hot forging dies it is important to observe this process from start. Because, any forming process is a cyclic process. And to analyze this process we need to generate cyclic stress-strain curve and give it as an input to analysis software so that results from that analysis will be more accurate [4].

For doing the same low cycle fatigue testing of die material was conducted and stress strain curves from the same is generated.
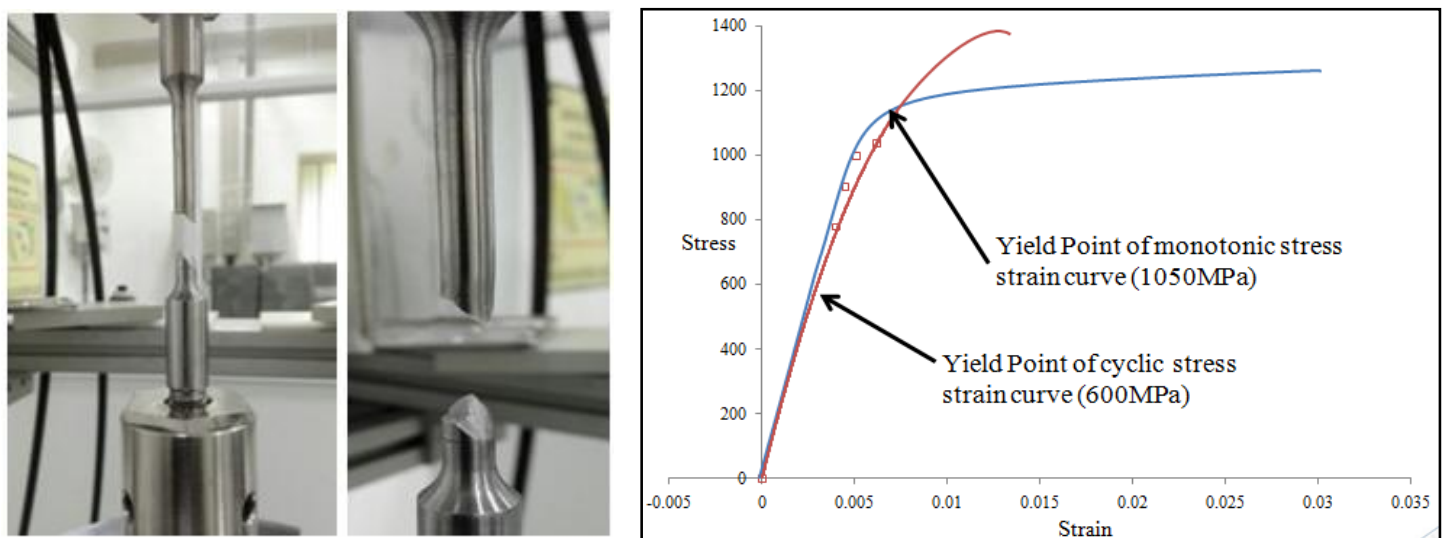

Fig.4. Specimen for low cycle fatigue test mounted on MTS and Cyclic Stress-strain curve for die steel material. 
By observing this stress strain curve, we can say that die material is softening at high stress zone. So to conclude this test we can consider it is a property of special steel like die material to get strain softened. Also its yield point reduces and it is almost $60-62 \%$ of original yield point [5].
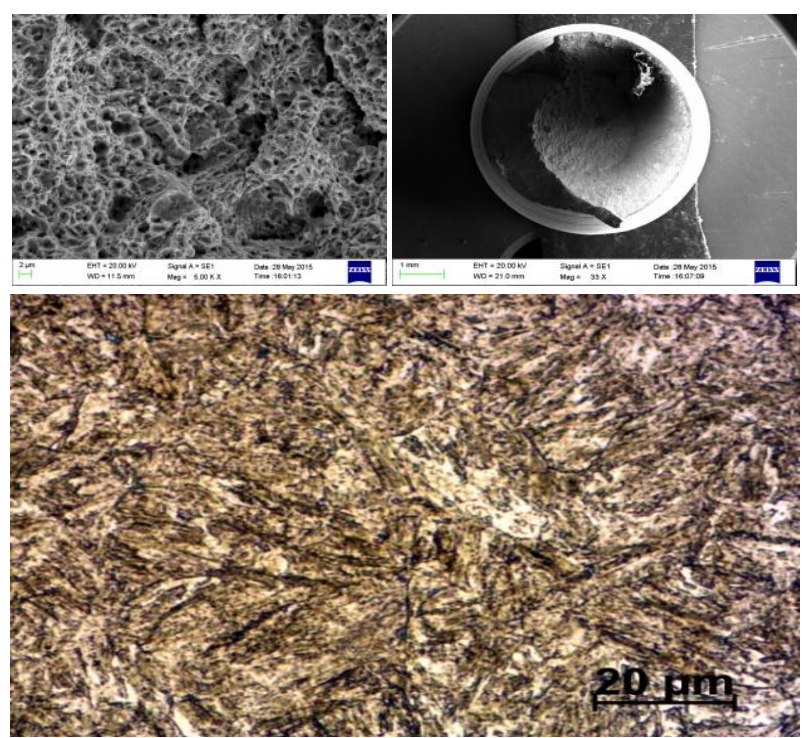

Fig. 5. Failed specimen of die material, microstructure and SEM images of failed sample.

When failed samples are investigated in Scanning Electron Microscopy (SEM), Dimple like structure states that, the failure of hard die material expected to be brittle but it is occurred in the ductile way. When microstructure images are studied, it has seen that there are some white patches with micro hardness level lesser than that of martensite but more than that of austenite. So it is named as soft martensite. This soft martensite plays an important role in strain softening mechanism for L6 steel.

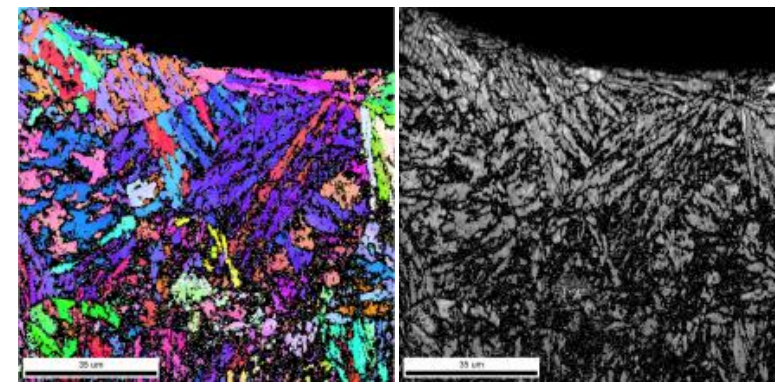

Fig 6. EBSD Analysis results of failed samples at strain rate 0.003 .

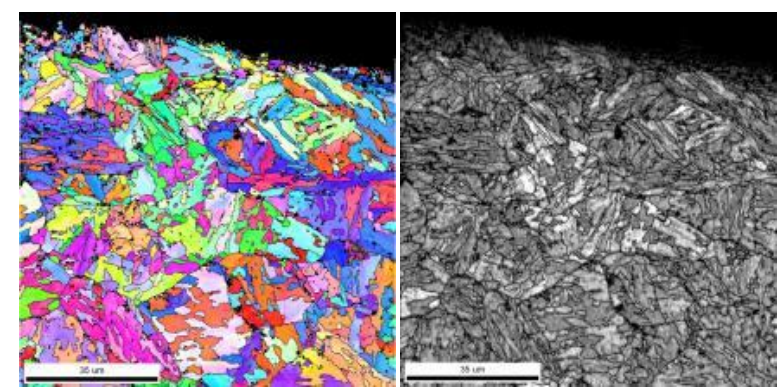

Fig 7. EBSD Analysis results of failed samples at strain rate 0.004 . 


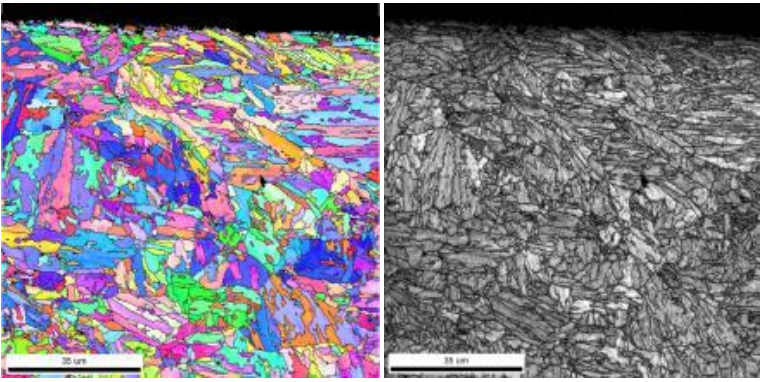

Fig 8. EBSD Analysis results of failed samples at strain rate 0.005 .

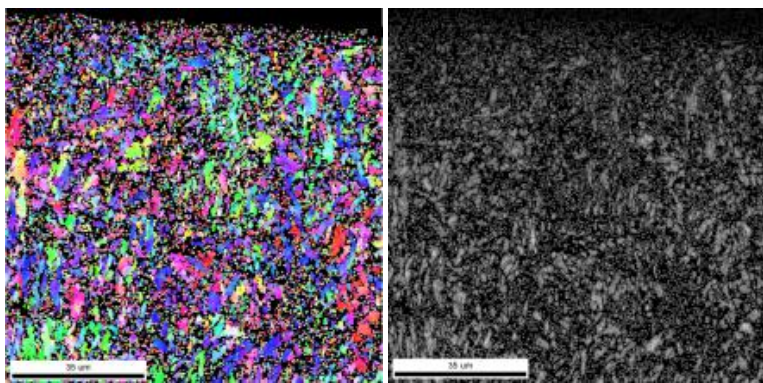

Fig 9. EBSD Analysis results of failed samples at strain rate 0.006 .

In the Fig. 6 to Fig. 9, it is clear that, when EBSD of Failed samples is carried out, then at low strain rate, grains are courser but as strain rate increases, grain splitting occurs and refinement is carried out below recrystallization temperature. In Fig. 8 grains are elongated and at the same point we are supposing material a transition from elastic to plastic for L6 Material. Fig 9 shows finer grains that means material is started to deform plastically. The main cause behind this is at carbides at high stresses become unstable and leaves their grain matrix. This leads to development of soft martensite patches in microstructure. Also for special steels like L6, they possess high dislocation density [6]. The cyclic loading offers rearrangements of dislocations, which offer less resistance to deformation and therefor material shows cyclic softening[7].

\section{Conclusions}

Metal forming is a cyclic process, so analysis of this process by monotonic stress-Strain curve fails to give accurate values of deformation. So to do accurate analysis instead of using monotonic stress strain curve, cyclic stress-strain curve is used. These values we get from are very nearer to actual shop floor values. Brittle material like die steel fails ductile while loaded in cyclic manner. It concludes that, Strain Softening is prone to happen in the material. Strain softening for special steels like L6, as it possesses high dislocation density. The cyclic loading offers rearrangements of dislocations, which offer less resistance to deformation and therefor material shows cyclic softening. This reduces yield point of the material from $1050 \mathrm{MPa}$ to $600 \mathrm{MPa}$. So to analyze the deformation, cyclic stress strain curve is useful rather than using monotonic stress strain curve. From EBSD Results it is clear that there is grain splitting occurs in the material at high strain rate. This increases the toughness and prolongs the failure but reduces the yield point and material prone to plastically deform. This enhances the deformation of die at low strain band and concludes in to premature die failure.

\section{Referances}

[1] Bay, N., Skov-Hansen, P., Gronbaek, J., \& Brondsted, P. (1999). Fatigue in cold forging dies: Tool life analysis. Journal of Materials Processing Technology, 95(1-3), 40-48.

[2] Caddell, R. M., \& Hosford, W. F. (1993). Metal Forming: Mechanics and Metallurgy. New Jersey: Prentice 
Hall Press.

[3] Collins, J. A. (1993). Failure of Materials in Mechanical Design: Analysis, Prediction, Prevention. WileyInter science Publication.

[4] Inamdar, S., Ukhande, M., Date, P., Lomate, D., Takale, S., \& Singh, R. K. P. (2017). Life prediction of L6 steel using strain-life curve and cyclic stress-strain curve by means of low cycle fatigue testing. IOP Conf. Series: Materials Science and Engineering: Vol. 201. IOP Publishing.

[5] Fatemi, A., Fuchs, H. O., Stephens, R. I., \& Stephens, R. R. (2001). Metal Fatigue in Engineering (2nd ed.). John Wiley \& Sons.

[6] Bannantine, J. A., Comer, J. J., \& Handrock, J. L. (1990). Fundamentals of Metal Fatigue Analysis. New Jersey: Prentice Hall Press.

[7] Bayer, R. G. (2002). Wear Analysis for Engineers. New York: HNB Publishing.

Mr. Sanket Prakash Inamdar is M.Tech from one of the most renowned institutes in India, i.e. IIT Bombay. He is working in Bharat Forge Ltd. From 2011 in the domain of Research and Development with expertise in the field of Fatigue, CAE and Mathematical modelling. He had published 3 research papers in various proceedings, IOPs and Journals. Also had given talks and presentations on various platforms like ISFT. He is involved in various projects like life prediction of hot forming dies, and a team member of project under India - Canada Collaborative research program, initiated by Indian government. 